\title{
Author Correction: Climate change and locust outbreak in East Africa
}

\author{
Abubakr A. M. Salih (D), Marta Baraibar, Kenneth Kemucie Mwangi $\mathbb{D}$ and Guleid Artan
}

Correction to: Nature Climate Change https://doi.org/10.1038/s41558-020-0835-8, published online 30 June 2020.

In the version of this Correspondence originally published, the funding information for authors A.A.M.S. and K.K.M., given in the first sentence of the Acknowledgements, was incorrect and should have read "A.A.M.S. is supported by the Climate and Development Africa Special Fund of the African Development Bank through the Satellite and Weather Information for Disaster Risk Reduction in Africa (SAWIDREA) project. K.K.M. is funded by the European Union through GMES and Africa project." The online versions of the Correspondence have been corrected.

Published online: 14 August 2020

https://doi.org/10.1038/s41558-020-0907-9

๑ Springer Nature Limited 2020

\section{Publisher Correction: Current and future global climate impacts resulting from COVID-19}

Piers M. Forster (D), Harriet I. Forster, Mat J. Evans (D), Matthew J. Gidden, Chris D. Jones (D), Christoph A. Keller, Robin D. Lamboll D, Corinne Le Quéré (D), Joeri Rogelj Di, Deborah Rosen, Carl-Friedrich Schleussner (D),

Thomas B. Richardson, Christopher J. Smith (D) and Steven T. Turnock (D)

Correction to: Nature Climate Change https://doi.org/10.1038/s41558-020-0883-0, published online 7 August 2020.

In the PDF version of this Article, the published online date was missing, and the date of ' 6 August 2020' given in the HTML was incorrect; this Article was published on 7 August 2020 and all versions have now been corrected.

Published online: 14 August 2020

https://doi.org/10.1038/s41558-020-0904-z

(c) The Author(s), under exclusive licence to Springer Nature Limited 2020 